\title{
Access to quality resources and environment and health issues
}

\section{Accès à des ressources de qualité et problématique Environnement et santé}

\author{
Anne Steenhout \\ Groupe d'Etudes Ecotoxicologiques sur les Polluants, la Santé et les Impacts sur l'Homme (GEEPSIH), \\ IGEAT (Institut pour la Gestion de l'Environnement et l'Aménagement du Territoire), \\ Faculté des Sciences; Université Libre de Bruxelles \\ asteen@ulb.ac.be
}

\begin{abstract}
:
Gaining access to air quality, to safe drinking water, to uncontaminated soil and crop, to a roof, is not warranted to everyone. This paper will present some historical or current environment and health issues that are rooted in the development of the industrialising society and the global economy. These examples question the links between contaminants impacts on ecosystems and on humans beings and modes of production that are responsible for unsustainability. Also, they provide an overview of the capability of our ecosystemic approach to address Environment and Health problems both in an integrated and a contextual way.
\end{abstract}

Keywords: Environment and Health, Ecosystemic approach, Environmental equity, Human rights, Risk from chemical substances, Precaution and vulnerable groups, Globalization

\section{Introduction: The industrial revolution and the environment}

Ecosystems have been more impacted since the industrial revolution than in other periods of time in human history. An example is deforestation. After intensive clearance of forests for extending agricultural soils, for heating, as building material, in shipyard, etc, deforestation had reached a critical level at the end of the $16^{\text {th }}$ century in Europe. For countries such England, on their way to industrialisation, the lowered availability of wood, lumber resources and charcoal leaded to an increasing use of earth coal to fulfil the need of energy. Coal became the fuel used in the development of steel industry, in steam machines, boat and rail transportation and in other, various, production sectors. The industrial exploitation of coal raised productivity by several orders of magnitude compared to before and contributed to other industrial innovation. Meantime, coal combustion amplified air pollution. London, for example, was especially undergoing smokes and fogs (i.e. smogs, by contraction of these 2 words).

Systems thinking is useful for understanding the processes and studying the history of industrial production in combination and for assessing risks from the emission of contaminants.

Other examples will be presented as well. Such associations occur also in the case of other productions and anthropogenic activities. With the industrial society, a variety of degradations of the environment quality involves a number of pollutants and all environmental media. Progress in analytical methods and 
increasing scientific knowledge raised the reliability of measurements (whereas reducing detection limits) and improved the identification of health effects under concentrations previously considered as safe. Dedicated time-related sampling protocols monitor environmental concentrations of a series of contaminants, such as heavy metals, on the local, the regional or the global scale. The understanding of the diffusion and circulation of contaminants - and in some cases, their accumulation - can be supported by speciation techniques. Their ability to identify anthropogenic sources through their chemical signature and to detect their occurrence, even in areas far from human activities, contributes to define a baseline (Figure).

\section{Fiqure:}

\section{The link between environment and development, our common future}

The recognition of the importance for mankind to protect ecosystems and the environment grew since the report "Our Common Future" (i.e. the Brundtland report) was published by the United Nations World Commission on Environment and Development in $1987^{1}$. The report linked environment and development as one single issue and considered that the reduction of poverty, gender equity and wealth redistribution are essential remedies to deal with it.

It recommended a sustainable course of development and took into account environmental limits to economic growth both in industrialised and industrialising societies. The report, however, did not question which modes of production are responsible for unsustainability and for the general environment degradation. Although, at the time of the report publication, the wording "sustainable development" was a synonym of changing the economic system, as it is not sustainable, further definition of a sustainable system was absent in the report.

The prominent influence of market-governed economic growth was not analysed.

In 2001, the European Commission, in preparing its strategy for a future chemicals policy $(\mathrm{REACH})^{2}$, insisted that the promotion of a non-toxic environment for protecting human health shall not jeopardize the competitiveness of the EU chemical industry but, rather, maintain and enhance it. The Commission sought to stimulate the development of safer chemicals through the new regulation. Meantime, based on full harmonization at Community level, the strategy aimed at ensuring the proper functioning of the Internal Market and at preventing its fragmentation.

\section{Risk assessment and environment protection contribute to human rights}

\footnotetext{
${ }^{1}$ Also, the "Limits to growth" report (known as the Meadows et al report (1972), commissioned by the "Club of Rome" thinktank had discussed and modelled 5 major trends of global concern. The book investigated scenarios and challenging global sustainability. At the time, the methodology and the conclusions were objected by certain economists.

${ }^{2}$ The proposal of the Commission White Paper (2001) on the strategy for a future chemicals policy concerned the creation of a single system for all chemical substances. In terms of assessing risks, priority was given to substances that leaded to a high exposure or caused concern. The document encouraged the substitution to less dangerous chemicals for dangerous chemical substances as soon as feasible, and the application of the precautionary principle, stipulating that "action must be taken even if there is still scientific uncertainty as to the precise nature of the risks. The REACH regulation (Registration; Evaluation, Authorisation of Chemicals) was adopted in 2005, based on the 2001 white book, with some modifications.
} 
Our ecosystemic approach addresses, in a continuum, industrial and other anthropogenic activities that contaminate the natural environment, and result in exposure and health effects. Primarily on the case of metals and gradually expanded to a generic approach to chemicals risks ${ }^{3}$, it elaborates from environmental epidemiological surveys as well as other tools and disentangles the contributions of multiple parameters, with a particular, precautionary, attention to time-related susceptibility to toxicants and to social and physiological vulnerabilities. Since its very first development, the approach built quantitative ways of evaluation of the efficiency of various actions for reducing the contamination and/or the exposure. It is aimed at assessing "how clean is clean enough" for protecting the entire population distribution and at identifying to which extent policy and risk management can still miss their objectives. The approach therefore naturally integrate in the picture societal issues such as a focus at low-income family, quality of housing and of the build environment, access to resources and other discrimination factors.

Awareness grow of international organizations that protection of environmental quality and protection of human rights strengthen each other. An analysis on the relationship between human rights and the environment (UN, 2011) has been conducted according to the request of United Nations Resolution 16/11. A series of components of the interaction between human rights and the environment were identified in the resolution. Among them, a positive statement is that "sustainable development and the protection of the environment can contribute to human well-being and the enjoyment of human rights", while on the contrary, "environmental damage can have negative implications, both direct and indirect, for the effective enjoyment of human rights". The resolution also recognizes that, "while these implications affect individuals and communities around the world, environmental damage is felt most acutely by those segments of the population already in vulnerable situations"

\section{Examples of integrating current contexts and societal issues}

\subsection{Access to water resources}

Other issues also have systemic characteristics. The way our society drives such access is one of the questioning in our integrated methodology. With the protection of vulnerable group and of future generations in mind, the approach, on one hand, assesses the risks from environmental exposure and on the other hand, also addresses the availability of quality drinking water, safe housing, indoor air quality, etc and only the access to resources themselves. We will further discuss here the case of safe drinking water,

The United Nations agreed on several Millennium Development Goals (MDGs) and targets ${ }^{4}$, among which the division by half, by 2015 , of the proportion of people without sustainable access to safe drinking water and basic sanitation. The phenomenon of refugees of the environment has shown not to be exceptional as well as wars for resources such as water. An assessment report from the United Nations (UN, 2012) indicated this MDG has already been achieved in 2010. About $80 \%$ of the world's urban

\footnotetext{
${ }^{3}$ http://difusion.academiewb.be/

${ }^{4}$ The internationally agreed framework of 8 goals and 18 targets was complemented by 48 technical indicators to measure progress towards the Millennium Development Goals (www.un.org/millenniumgoals/ http://www.unmillenniumproject.org/goals/core $\mathrm{mdgs} . \mathrm{htm}$ ).
} 
population had piped water connections, compared to only $29 \%$ of people in rural areas (Table). However; despite the progress noted, the $\%$ of access varies widely among regions ${ }^{5}$.

$\underline{\text { Table }}$

With more than 120 million European people living below the poverty line and at risk of social exclusion, Europe had to work further on what was recently recognized as a universal right. Two opposite visions occur among stakeholders. In the Water Manifest for a World Water Contract by the Group of Lisbon in 1998, fundamental of the campaign was that water is not merchandise. Water belongs to all inhabitants on Earth and access to it should be free and sustainably managed. Water companies consider this in a different way. What is considered as a right by alter-globalization is viewed, on the contrary, as a need that consumers need to fulfil. According to this, water is a good to which a universal access is granted under the condition of a fee and the complexity of the current global economic system would make it impossible to do otherwise.

One can note that the current method of monitoring in the UN programme is assessing progress based solely on the types of facilities used. Data are scarce on some important parameters, such as drinking water quality. the availability of adequate quantities of water for domestic use, the number of service hours available, the distance to a water source or sanitation facility, or the time household members spend on access and use of sources and facilities. Beside, estimates about another MDG, relative to coverage of $75 \%$ of families with water sanitation services, suggest that this objective is still out of reach at the 2015 deadline. In France, 1\% of the population do not have drinking water at the house and $15 \%$ are not connected to a collective sanitation network, mainly in rural areas.

The integrated approach addresses, among other parameters, the sources, lifestyles and determinants of exposure to contaminants. Then, it study to which extent social factors influence the quality of the living environment (Table) and quantify the risks from exposure under unequal living conditions. While data are specific to these areas under examination, coherence validation tests result in useful generic information.

\section{Table}

\subsection{Environmental conflicts in a globalized world}

Investigations and exploratory soil studies are processed in various parts of the world by Cies, in order to locate areas interesting for mining and extraction activities. Costs and benefits analyses result from, including further costs and transportation. For these areas where the balance is positive and where the period of time needed before getting the investments back is considered as short enough, extended surfaces are bought and a proposal of exploitation is emitted. Environmental conflicts can arise.

\footnotetext{
${ }^{5}$ Indeed, the progress of India and China (with about $46 \%$ of the developing world's population) represents nearly half of the global progress towards the drinking water target. On the contrary, in a significant part of Africa, the coverage rate in 2010 was the same or was lower than the rate in 1990 or below $10 \%$ of the 2010 rate required to meet the MDG target, and it is not on track to meet the target by 2015. Also, in certain countries, gains in the people served can be masked in countries with a combination of low baseline coverage and high population growth rate. An alternate indicator, expressed as the increase since 1995 in the number of people with access as a proportion of the current (2010) population showed that even countries that are off track in terms of MDG progress have raised the number of people served.
} 
One example of this concerns the proposition of exploitation of a copper mine in South America. Acceptance of this project could significantly change the entire department from a use primarily oriented to farming, to an industrialized mining region. The concession, established in 2002 by a British and Asian Cy in association, was aimed at producing about $\$ 1$ billion worth of copper within the next 20 yrs. The territory shelters a forest and major rivers and local communities rely on farmland and livestock. It also houses endangered species in a part of the area. The way globalized enterprises put into practice the exploration phase of indigenous territories, looking for mineral deposits, can raise concern. In the example above, the lack of democratic participatory approach was noticeable and did not follow regional policy. A non-binding referendum was organised by citizens to express their acceptance or refusal of mining their community turnouts against the project. A law suite issued by the national government followed as well as arrest and detention of citizens participating to a demonstration. Violation of their physical integrity and their human rights occurred and a complaint was filled to the Human Rights Committee at the country level. For various reasons, the Cy project got suspended but not definitely stopped. As the Cy is intended to reopen the file for starting operation in 2013 and the population is still against it, further conflicts may occur.

There are a number of areas tested for the possible financial interest of mining activities. Other examples will be presented.

An Environmental Impact Assessment (EIA) is the norm before exploitation. Transparency is necessary. The quality, both of exploratory information and of impact studies need, however, additional, independent, assessment, to be performed by an instance with no link to industry. Evaluating the adequacy of the indicators selected is important as well, so that risks can be assessed in an integrated way.

On the level of international organisations, the UN Resolution (quoted above in §3) also recognizes that "many forms of environmental damage are transnational in character and that effective international cooperation to address such damage is important in order to support national efforts for the realization of human rights".

\section{References}

Commission White Paper of 27 February 2001 on the strategy for a future chemicals policy -COM (2001) 88 final ( http://europa.eu/legislation summaries/other/l21275 en.htm).

\section{Steenhout A in http://difusion.academiewb.be/}

UN (2011). Analytical study on the relationship between human rights and the environment. Report of the United Nations High Commissioner for Human Rights. Human Rights Council, United Nations General Assembly http://www.ohchr.org/Documents/HRBodies/HRCouncil/RegularSession/Session19/A-HRC-19-34 en.pdf

UN (2012). Progress on Drinking Water and Sanitation. UNICEF and WHO 2012 UPDATE report of the Joint Monitoring Programme (JMP), http://www.who.int/water sanitation health/publications/2012/jmp2012.pdf 